\title{
Medicines Reclassification from a Pharmaceutical Industry Perspective: an
}

\section{International Qualitative Study}

\section{Natalie J Gauld $^{1 *}$, Fiona S Kelly ${ }^{2}$, Lynne M Emmerton ${ }^{3}$,} Nahoko Kurosawa ${ }^{4}$, Linda JM Bryant ${ }^{5}$, and Stephen A Buetow ${ }^{6}$

1 Honorary Senior Clinical Lecturer, School of Pharmacy, The University of Auckland, Auckland, New Zealand; Phone: +64 21336 685; n.gauld@auckland.ac.nz

2 Senior Lecturer, School of Pharmacy and Pharmacology, Griffith University, Queensland, Australia; f.kelly@griffith.edu.au

3 Professor, School of Pharmacy, Faculty of Health Sciences, Curtin University, Perth, Australia; Lynne.Emmerton@ curtin.edu.au

4 Professor, Faculty of Pharmaceutical Sciences, Hokkaido University of Science , Sapporo, Japan; kurosawa@hus.ac.jp

5 Honorary Research Fellow, Department of General Practice and Primary Health Care, The University of Auckland, Auckland, New Zealand; 1.bryant@auckland.ac.nz

6 Associate Professor, Department of General Practice and Primary Health Care, The University of Auckland, Auckland, New Zealand; s.buetow@auckland.ac.nz

* Author to whom correspondence should be addressed; n.gauld@ auckland.ac.nz

\section{Acknowledgments}

We gratefully acknowledge the assistance of the pharmaceutical industry stakeholders who participated in research interviews. Grants from New Zealand Pharmacy Education and Research Foundation and The University of Auckland partially supported travel undertaken in this study.

\section{Author Contributions}


NG designed the research with supervision from LB, SB and FK, conducted and analysed interviews, reported findings, and wrote the first draft of this paper. LE had an advisory role. NK provided input into the Japan selection and recruitment of participants, data collection and analysis. All co-authors provided input into reporting and contributed to the writing of this paper.

\section{Conflicts of Interest}

NG reports consultancy fees relevant to reclassification from Green Cross Health, Pharmacy Retailing, Douglas Pharmaceuticals and Perrigo, and unrestricted research funding from Roche Pharmaceuticals, outside of the submitted work. NG was a member of the Medicines Classification Committee in New Zealand (2004-2009), and is a member of the Board of the Pharmaceutical Society of New Zealand. Since completing the final report of this research, NG reports consultancy fees and/or travel for speaking engagements from Novartis Consumer, Sanofi Aventis, Pfizer, the Australian Self-Medication Industries, the Pharmacy Guild of Australia, the Association of the European Self-Medication Industry (AESGP), the Irish Pharmacy Union, and Bundesverband der Arzneimittel-Hersteller. NK reports personal fees from Kaigen Pharma Co., Ltd, outside the submitted work. The other authors declare no conflict of interest. 


\section{Medicines Reclassification from a Pharmaceutical Industry Perspective: an}

\section{International Qualitative Study}

\section{Abstract}

5 Background: Widening access to medicines through reclassification ('switching') of

6 medicines from prescription to non-prescription is an international trend generally welcomed

7 by community pharmacists. Research has focused on scheduling and committee deliberations

8 affecting reclassification, rather than industry aspects, despite industry's role in driving

9 reclassifications. The research aimed to identify how pharmaceutical industry and

10 product-related factors influence reclassification, and to explore stakeholder acceptability of

11 government or third-party driven reclassifications.

12 Methods: Sixty-five in-depth, semi-structured interviews were conducted with 80 key

13 informants (representing regulatory bodies, industry, pharmacy and medicine) in developed

14 countries including the United States, the United Kingdom, Japan, Australia, and New

15 Zealand. The questions explored barriers and enablers to reclassification at the local (micro-),

16 regional (meso-) and global (macro-) levels. Analysis of transcribed interviews entailed

17 descriptive and thematic approaches.

18 Results: Pharmaceutical industry decisions to drive medicine reclassification reflect

19 characteristics of the company, product, and external environment at all levels. For the

20 company, financial factors, company focus (e.g. on prescription business versus non-

21 prescription business), and capability in non-prescription medicines and reclassification were common influences. Products with significant non-prescription market potential and a wellknown prescription medicine brand name most suited reclassification, usually near patent expiry. Barriers included immediate generic entry post-reclassification, and a short-term profitability and/or prescription business focus. Some countries allow government or a third- 
26 party (including pharmacy) to drive reclassifications, with examples of successful

27 reclassifications ensuing. Some industry and other participants held concerns about this

28 practice, particularly in the United States. Concerns included insufficient resourcing, and the

29 pharmaceutical company's business, potentially encouraging product withdrawal or legal

30 challenge.

31 Conclusions: This study is the first to explore both pharmaceutical industry factors affecting

32 reclassification and acceptability of alternate drivers of reclassification. Factors beyond

33 clinical safety and efficacy and the local reclassification environment can influence

34 reclassification. Pharmacy-driven reclassification might be one alternative. 


\section{Medicines Reclassification from a Pharmaceutical Industry Perspective: an International Qualitative Study}

\section{Introduction}

Widened access to medicines through reclassification from prescription to non-prescription can offer consumers timely and convenient access to safe medicines, conserve health care resources and expand the use of the clinical skills of community pharmacists. ${ }^{1-3}$ However, risks include misuse, inappropriate use, and delayed diagnosis. Occasionally, reclassification decisions are reversed on account of safety and usage data postreclassification, as for example with oral diclofenac in the United Kingdom (UK), or are withdrawn owing to low sales, e.g. simvastatin in the UK. ${ }^{4}$ However, medicines continue to be reclassified in many different countries. ${ }^{5}$ Recent international reclassifications include more complex target areas such as antimicrobials, chronic conditions and prevention of disease. ${ }^{5}$ Pharmacists often welcome this development. ${ }^{6-8}$ However, some potential reclassifications do not actualize. In the United States (US) in 2012 the Food and Drug Administration (FDA) suggested that reclassifing medicines could alleviate under-treatment of conditions like hypertension and asthma, ${ }^{9}$ but no such reclassifications have been forthcoming. Despite calls for reclassification from Lancet editorials, ${ }^{10,}{ }^{11}$ specialists, ${ }^{12,}{ }^{13}$ women, ${ }^{14,15}$ and medical associations, ${ }^{16-18}$ and despite evidence supporting supply by pharmacists, ${ }^{19,} 20$ women still require a prescription for (non-emergency) oral contraceptives in most Western countries. ${ }^{21}$ Many medicines that were suggested in the UK for non-prescription availability in $2002^{22}$ remain prescription-only. Since medicine reclassification depends largely on the pharmaceutical industry driving applications forward, ${ }^{23}$ it is important to understand barriers and enablers experienced by the pharmaceutical industry. 
Pharmaceutical companies can benefit from reclassifying a medicine through increased sales ${ }^{24}$ the ability to set pricing, ${ }^{25}$ and brand longevity, particularly after patent expiry when generic competitor products take share of the prescription market. ${ }^{26}$ Despite these benefits, companies are choosing not to reclassify some potential candidates. Commentary has been published about the industry perspective on reclassification, ${ }^{27-29}$ usually in a single country. However, in generally overlooking the role of industry, academic research has focused on committee decision making, and regulatory and other influences on reclassification. ${ }^{30-36}$ Governments $^{31,33,37}$ and third parties ${ }^{38-40}$ sometimes drive reclassifications, and pharmacy organisations may encourage government reclassification or drive reclassification themselves.

The parent study aim was to identify the factors that determine variations in how high-income countries reclassify medicines from prescription to non-prescription. We have previously reported influences 'external' to the pharmaceutical company and product. ${ }^{38,41}$ For Australasia, factors affecting reclassification at a regional level, primarily 'external' to the pharmaceutical company and product, have also been reported. ${ }^{40}$ However, this paper aims to consider the novel perspective of how pharmaceutical company and product factors interact with the external environment nationally, regionally and globally to influence pharmaceutical company submissions of reclassification applications. Since industry does not drive some potential reclassifications, this paper examines stakeholders' perspectives of having non-industry drivers.

\section{Material and methods}

The University of Auckland Human Participants Ethics Committee approved this study (approval number 2008/304). The research study design used interpretive description for applied practice, ${ }^{42}$ and a qualitative heuristic approach ${ }^{43}$ to utilize the knowledge, experience and active input of 
the lead researcher to draw on her rich background in the area. Her involvement in reclassification included medicine classification committee membership, previous communication with stakeholders about reclassification in several countries, post-reclassification research, and preparing reclassification applications. As an 'insider' or co-participant in this research, she engaged with the participants to investigate the subject material while reflecting critically on how this engagement influenced her conduct of the research. Detailed elsewhere, ${ }^{38,41}$ the research methods are summarized here. Countries selected included five "highly-developed" 44 countries for in-depth analysis - the UK, US, Japan, Australia and NZ - supplemented for breadth by the Netherlands, Denmark, Canada, and Singapore. We sought to maximize variation among participants selected within and across these countries ${ }^{43}$ while always speaking with those most informed about the topic. ${ }^{45}$ Key informants were selected purposively from regulatory agencies, pharmaceutical industry, academia, and pharmacy, medical and consumer organizations, and committees considering switches of medicines, as agreed by the research team. At each contacted organization, a request was made to interview the person (or people) working most on that topic. Snowballing helped to identify other experts. Some participants in Australasia and the UK were already known to the lead researcher, given her work in the field, and some in Japan were suggested by a Japanese co-author. The resultant sample enabled country-by-country comparisons, exploration of regional effects and observation of 'global' influences.

The lead author interviewed participants, usually for one hour, using a semi-structured approach, ${ }^{43}$ guided by core questions on enablers and barriers to reclassification activity (Panel 1). ${ }^{41}$ Data saturation was not sought, owing to the limited number of persons available in each country with switch experience, and a desire to explore a range of perspectives from different countries and different stakeholder groups. Conducted over a 3-year period ending in 2012, the interviews were audio-recorded and transcribed verbatim and/or notes were taken and supplemented if 
necessary by email questions. The interviews were read and re-read. Key segments of text were systematically coded and grouped thematically in context, using qualitative software, NVIVO 9. Document analysis (e.g. minutes of meetings on reclassifications) supplemented and/or triangulated the interviews. The lead author using a general inductive approach, conducted descriptive and interpretive analysis of themes identified from the data. The themes were interrogated with respect to participant attributes. Barriers and enablers were documented by country and reported elsewhere. ${ }^{38,41}$ For this paper, product-related, company-related factors and views on non-sponsor reclassification were elicited from the coded data. Skeptical peer review and participant checking contributed to the trustworthiness of the data analysis.

\section{Results}

\section{Participants' characteristics}

Eighty key informants were interviewed in 65 interviews (48 face-to-face, the rest by telephone or video-call). Most participants (n=65) represented experience in the UK, US, Japan, Australia and NZ, with 11 participants drawn from the other countries. Some participants had a regional or global role, and had worked in one or more countries. Such participants are described as regional industry participants or global industry participants, respectively. While most participants reflected a single role, some reflected two roles, e.g. a committee member and a regulator. Further details on the sample are provided elsewhere. ${ }^{41}$ For pharmaceutical industry factors influencing reclassification, the primary data analysis used interviews of 21 industry participants who were usually highly experienced with reclassification. Five had experience with the NZ market, 5 with the Australian market, 6 with the Japanese market, 3 with the US market, and 2 with the UK market. Two participants had 
regional Asia-Pacific experience, 2 had pan-European experience, and 3 worked at a global level. Industry participants came from the industry organizations, multi-nationals, generic companies and local distributors. For product factors and views on non-sponsor reclassification, data were drawn from industry and other participants. External, pharmaceutical company and product related factors affected reclassification at a global level, a regional level (e.g. Europe or Australasia) and an individual country level (Figure 1). ${ }^{41}$

\section{Pharmaceutical company factors}

Factors affecting the pharmaceutical industry broadly aligned with 4 key areas that sometimes overlapped: cost and return of the nonprescription opportunity; effects of the reclassification on the prescription business; reclassification capability and attitude; and regional and global effects. These areas gave rise to factors for individual companies (company factors) whose interaction with external factors and product factors stimulated (enabled) or inhibited (provided barriers to) reclassification in different markets. Figure 2 illustrates the multi-factorial nature of decision-making at the regional level, reported by participants from NZ and Australia with experience of NZ reclassification, including 3 NZ industry participants, and 3 Australian industry participants. Relationships between factors are shown from interview data. Although financial motivations were a major consideration by pharmaceutical companies in choosing whether or not to reclassify a medicine, other factors were important, and varied by company. Some companies viewed reclassifications more favorably than others, and interest could vary over time.

\section{Financial aspects}

The financial feasibility of a reclassification was important with reclassifications competing internally with other company projects for funding. 
... there really is limited budget to spend on all of your initiatives, and that includes switch, but it includes a lot of other things too.

Switch ... can be a small part of the portfolio, but it can be a big contributor if you can get a new one through.... For a complicated switch, it can range anywhere from 30 to 50 million [dollars] in investment.... You have significant milestones [where you] ... rethink, is it still worth our investing? (US industry participant)

Several participants reported that the short-term focus on returns of non-prescription medicine companies conflicted with the long reclassification process in some countries and delayed returns.

... most reclassifications fail outside of the US, and the ones that succeed-it's a very painful journey ... If they do pay back, it takes a long time... (Industry participant working at a global level)

The prescription business could reportedly have a significant effect on the decision to reclassify, often providing a barrier to reclassification, sometimes even after patent expiry.

... you look at sales volumes and profitability, it's $80 \%$ Rx [prescription] and 20\% OTC [non-prescription], at best.... And so, ultimately the decisions are made on the basis of Rx thinking. (Industry participant working at a global level)

Internal conflict reportedly prevented or delayed some reclassifications, with reluctance by the Prescription division to lose sales to the Consumer division, or a company decision to keep a product on the prescription side. For example, an asthma reliever inhaler (salbutamol) that 
had long been reclassified remained with the Prescription division of a company in Australia. Salbutamol inhalers reportedly stayed prescriptiononly in the UK because no company attempted the reclassification.

Overall, financial ramifications indicated by participants as a barrier to reclassification could include loss of prescription sales from doctor backlash, or loss of prescription subsidy (e.g. the Netherlands). A reclassification might not progress if it could lower the hurdle for a generic competitor to register in the market, facilitating market entry of a competitor and potential loss of prescription sales. Conversely, a reclassification was occasionally reported to help prescription sales (and enable reclassification), e.g. through advertising the non-prescription version to consumers. These different effects indicate how financial ramifications for a company arise from a mix of factors, particularly local market factors. For example, in Japan, industry participants reported that strong prescription sales after patent expiry, low non-prescription sales, and fear of doctor backlash strongly inhibited their interest in reclassification. Therefore, some companies tended not to pursue reclassifications, or to take considerable time to decide to pursue a reclassification, as in the case of a low dose anti-inflammatory which "took more than several years to get approval within the company".

Company capability with and attitude to reclassification

Multi-national companies with consumer health and prescription divisions were said to drive most reclassifications, typically using products their company had developed, as confirmed with document analysis. Generally, they had in-house expertise in submitting switch applications and marketing switched products, as well as managing well-known brand names to aid sales post-switch. However, interest within companies for reclassification was noted to vary, with one large multi-national consumer health company reportedly preferring line extensions of non- 
prescription brands rather than reclassifications, given greater return on investment. Multi-national innovator companies with no consumer health business reportedly usually had little interest in reclassification, having the barrier of no marketing or distribution expertise, focus or sales force for non-prescription work. Instead, they might license products with high potential in the non-prescription market to a consumer health company as the patent expiry approached, as did Astra Zeneca with omeprazole (for heartburn). In contrast, a participant reported that a company without a non-prescription field force bought a consumer health business to maximize capability for an upcoming US reclassification.

Participants described how generic pharmaceutical companies generally do not drive reclassifications. Often they are prescription-oriented, without well-known prescription brand names from which to leverage reclassifications, reclassification knowledge or expertise to build a strong brand. However, there was an exception: 2 participants described how a UK generic company, Galpharm, had developed a workable sales model for multiple reclassifications.

Another industry player identified in this research was the distributor or licensee of a product in a particular market. Two NZ participants from distributors noted how the temporary and local nature of distribution provided a barrier to wanting to invest for long-term gains. The company that owned the brand, with whom they had a distribution agreement, could veto a reclassification the distributor wanted. Document analysis showed that distributors seldom drive reclassification.

Participants noted that attitudes to reclassification and business focus changed with a company sale, merger, or different boards or executives, affecting reclassification. This was likely with tranexamic acid in Australia as seen in our document analysis. Reclassified in 2000, it was not 
launched. It returned to prescription status in 2007 in the absence of interest from the product sponsor, which underwent mergers in 2000 and 2003.

NZ and UK participants mentioned that limited company manpower restricted internal resources available for reclassification work.

\section{Regional and global effects}

Internal strategy, resources, and opportunities available locally, regionally and globally, affected multi-national company decisions on reclassifications. Sales in the US market for reclassifications could be worth hundreds of millions of dollars. Thus, the US market could influence companies' actions elsewhere, encouraging reclassifications or preventing reclassification applications outside the US.

About $80 \%$ of triptan volume, when it's reclassified everywhere, if ever, will come from the US.... So if you make a loss-making UK test market ... to show there are no side effects, no-one died, everyone's happy,... that's what statins and triptans in the UK are all about. (Industry participant with global responsibilities)

One industry participant reported that an oral contraceptive manufacturer would not risk reclassifying non-emergency oral contraceptives anywhere, owing to the expected backlash from US consumers. Participants reported reclassifications not pursued in the UK and NZ owing to concerns about effects elsewhere.

...doubling sales in NZ, a company wouldn't see that is a benefit if there is even a tiniest effect in the rest of the world. (NZ industry participant) 
Interest in reclassification was limited in small markets, although it may eventually follow other countries.

...if you were going to go for a major global switch of something yes of course it would fall in line and we would get around to it in Singapore... (Industry participant with a previous Asia Pacific regional role)

Sometimes reclassifications occurred early in a small country to help another market, e.g. as a test market. Two Australian participants revealed that companies sometimes attempted reclassifications in NZ to assist an Australian reclassification attempt. However, in another example of regionalism, having off-shore regulatory staff and marketers could hinder reclassifications, or understanding of the reclassification process and environment in a small market, as described for chloramphenicol eye drops in NZ. Local branches of multi-national companies may only be allowed to reclassify a product if the global office agrees; alternatively, the global office may insist on it:

The first reclassification we did was Imodium ${ }^{\circledR}$ [loperamide for diarrhea], and the prescription guys were really, really against it... it was forced on us by our American [head office] and so we did the reclassification... it's a global brand now... (UK industry participant)

One company that successfully drove multiple reclassifications in the UK, including chloramphenicol eye preparations, omeprazole and naproxen was Galpharm. Part of its success in reclassification was attributed to it being a local UK company, not needing to consider global issues. Unlike large multi-nationals, it could start and stop projects quickly and it was not limited to the company pipeline, i.e. to products that it had developed. It focused on finding further medicines to reclassify and had an employee who was highly experienced in reclassification. The government support for reclassification in the UK provided a positive environment for Galpharm's applications. 
Regional and global effects were evident for all 3 interacting groups of factors - external factors, company factors and product factors (Figure

1). Our earlier papers reported regional influences in Australasia and Europe. ${ }^{38,41}$ A wider international effect also occurred.

\section{Product factors}

Companies considered product factors in deciding whether or not to reclassify. These included safety aspects, and minutes from NZ in the early 1990s show companies opposing government or committee-suggested reclassifications on the basis of safety. Other factors include likelihood of reclassification approval, market potential, and the cost and effort of reclassification.

... can you reclassify it; but then can you sell it? ... In some instances, it is easier to get it approved than it is to get it accepted by the consumer. (Industry participant working at a global level)

Participants described commercially unsuccessful reclassifications, e.g. simvastatin (for preventing heart disease) and omeprazole (for heartburn) in the UK.

...the $\mathrm{H}_{2}$ antagonists [for heartburn] were a big failure outside of the United States.... Japan it was a disaster, 13 famotidine brands launched on the same day, and 12 of them withdrawn within 2 years.... $\mathrm{H}_{2}$ s in the first 4 years in the UK spent $\$ 30$ million on advertising to create $\$ 4$ million in sales. (Industry participant working in a global role)

Companies typically internally reviewed safety aspects of potential reclassifications early in the consideration, to mitigate their concerns about risk and assess the likelihood of approval. 
Industry participants reported that various factors contributed to consumer uptake of a reclassified medicine. The retail cost of the product could deter consumer purchases, particularly where obtaining a prescribed alternative was much cheaper. One participant suggested that a small therapeutic advantage in a clinical trial might influence a prescriber but be unnoticed by the consumer, who will not pay a premium. Consumer uptake could be unpredictable, as evident in an experienced participant expressing surprise that non-prescription sales of triptans (for migraines) were higher in Germany than the UK.

... there's a lot of chance in these things-like Voltaren Emulgel ${ }^{\circledR}$ [an anti-inflammatory medicine applied to the skin] was a great surprise at how successful it was... but sometimes something just hits the public. [Industry participant working in a global role] Patent expiry was important. Medicines that were long off-patent had low attraction with a low price point, and immediate generic competition post-reclassification in some markets. Companies often applied to reclassify medicines just before patent expiry given their expected prescription price and sales decline. This motivation depended on external factors in a market, e.g. patent effects appeared strong in the US, where: prescription pricing on patent could be higher than that achievable for a non-prescription medicine, 3 years of market exclusivity is possible on reclassification, and prescription sales of an innovator medicine decline considerably after patent expiry. Product characteristics that created difficulty for a generic competitor to enter the market made reclassification more attractive, e.g. difficulty manufacturing nicotine replacement therapy limited potential competition.

Other product factors affecting the potential payback (and therefore company interest) included the size of the target population, potential for repeat use, and brand strength. 
If you've got a good strong brand and you think you can extend that brand equity into the [non-prescription market], then you are more likely to be willing to invest in [reclassification]. (Industry participant working in a global role)

Product factors affected the cost of reclassifying with respect to associated requirements, depending on the country. For example, attempts to reclassify statins required expensive studies in the US, and development of screening tools, pharmacy training and a post-marketing surveillance study in the UK. Product complexity, such as complicated dosing, uncertainty about usage, or need for extensive screening tools could impair sales, as UK participants described for tamsulosin and simvastatin. Various participants reported that the "easy" reclassifications had been accomplished, with difficult ones remaining.

Multiple product factors may be involved, combined with external and company factors (Figure 1 and 2):

Azithromycin [an antibiotic for Chlamydia infections] ... it's ridiculously expensive OTC [without prescription], and again, it's this ridiculously cumbersome protocol ... young people either ... will be getting themselves checked up regularly at what we used to call STD [sexually transmitted disease] clinics, and azithromycin is cheap there ... or they're totally ignorant and they won't be doing anything about it ... (UK industry participant)

Niche products are typically ignored, particularly in the US, where the high cost and long time-frame of reclassifying makes return on investment difficult, unless the reclassification is easy.

\section{Reclassifications driven by non-sponsors}


Many participants outside of the US believed it was reasonable for non-sponsors to drive reclassification. Some participants, including regulatory participants, noted the potential for non-sponsors such as government, funders or pharmacy to drive reclassification to help manage resources, e.g. costs or workforce, or facilitate access.

Some industry participants voiced some concerns about government or third-party reclassifications, including in countries in which it had occurred, and negativity existed in the US to the idea. Concerns, for example about facilitating generic company entry or dereimbursement (removal of prescription subsidy), could stimulate company activity to try to stop the reclassification or otherwise manage it, e.g. discontinuing the product in the market where it was reclassified (if the market was small), or discontinuing packs that would become non-prescription.

However, a minority of industry participants were open to the idea:

... if you've got an evidence-based process which is transparent to everyone, the company could have a chance to comment on that as could everyone else. I don't have a problem with other groups doing that. (Industry participant in an Asia-Pacific regional role)

In the US, the typical reclassification model is just before patent expiry, often gaining a further three-year market exclusivity for the studies conducted for the reclassification. A forced reclassification could therefore have significant commercial ramifications, compounded with price drops and loss of health funder reimbursement which usually occur after reclassification.

...many of the bigger companies would challenge if FDA [Food and Drug Administration] came and said yes, we have the authority to switch a product, whether the company wants to or not. (US industry participant)

Mechanisms for third-party reclassification 
In NZ and Australia, anyone can apply to reclassify a medicine. In both countries, a pharmacist-only category may facilitate non-sponsor driven reclassifications, as health professional involvement may reduce the need for consumer labelling. A consumer information sheet has sometimes been developed independent of the product sponsor for such reclassifications in NZ, for example with chloramphenicol and trimethoprim. We have separately reported a case study on the NZ third-party reclassification of calcipotriol. ${ }^{39}$

Participants reported that the UK requirement that an applicant had to be a license holder for the medicine would stop non-sponsor reclassifications.

The US has a mechanism to allow Citizen's Petition for reclassification, but it appeared unworkable without a company application. The attempt by Wellpoint (a health insurer) in 1998 to reclassify non-sedating antihistamines got nowhere until a company eventually applied to reclassify loratadine, approved in 2002.

FDA [Food and Drugs Administration] won't act on the petition unless they have an application from the company that they can actually approve. (US industry participant)

'Cos generally I think the tack has always been in law that these products are the property of their companies. And that they kind of get to pick how they want to market them. And then FDA has the authority to say no you can't do that or yes you can do that. (US regulatory participant) 
Other barriers to non-sponsor reclassification in the US include the need for consumer label comprehension, self-selection and actual use studies required for many reclassifications.

\section{Government- or committee-driven reclassifications}

Several participants noted the restricted resources of government to drive reclassifications. However, a NZ participant described cases where the government had a particular interest and stimulated the reclassification, e.g. political interest in sexual health put the emergency contraceptive pill on the reclassification agenda.

NZ also saw a committee-driven reclassification without a company application. The committee made chloramphenicol eye drops an agenda item, and approved it, with some information from the UK and a commitment from the Pharmaceutical Society of NZ to provide training and practice support materials. This created some difficulties for the distributor with short notice to change drug labels.

A participant from Singapore described how the regulatory body periodically reviewed candidates for reclassification and initiated a reclassification if a company had not applied for a reclassification, usually working with the sponsor company involved. The Pharmaceutical Society in Singapore was proactive in meeting with companies and the medicines regulator to encourage reclassifications, and surveyed pharmacists as to what they wanted reclassified. 
Although Denmark reclassified a number of medicines from prescription to non-prescription in the late 1980s without company applications, this was no longer happening. However, the medicines regulator regularly reviews a list of pharmacy-only medicines to consider if wider availability might be suitable.

\section{Third-party reclassifications}

Third-party reclassifications, driven by a party other than the sponsor or the government/committee are uncommon. There was considerable variability amongst pharmacy representatives about the idea of reclassifications being driven by pharmacy organizsations. Several participants in NZ (academic, regulatory, pharmacy) suggested that pharmacy should drive reclassifications, but another pharmacy participant held concerns, thinking the medicines regulator should do it instead:

[We] don't have the resources, don't have the information and anyway [the medicines regulator has] got all that stuff in the registration of the product in the first place. (NZ Pharmacy participant)

Lack of resource was also cited by an Australian pharmacy participant as to why pharmacy organizations would not drive this in Australia. A pharmacy participant from the Netherlands considered that the manufacturer needed to drive the reclassification to provide appropriate labeling. However, a UK pharmacy participant indicated that pharmacy-driven reclassification would be "a really good and positive move”, noting that a particular medicine (naloxone) that could usefully be reclassified had not been. 
Subsequent to some of the NZ interviews, reclassifications were successfully driven by a primary health care services provider (Green Cross Health) that represents or has shareholdings in many NZ pharmacies but is not a sponsor for the reclassified medicines.

In the US, participants representing pharmacy organizations were ambivalent about reclassification, so pharmacy was unlikely to try to drive it. It was also clear that US pharmacy groups were driving services in other ways, so reclassification was not important.

\section{Discussion}

As reclassification expands pharmacy services, it is important for pharmacy organizations and pharmacy leaders to understand barriers and enablers to the pharmaceutical industry driving reclassification, in order to be able to influence these forces where possible. Non-sponsors, including pharmacy organizations, may be able to drive reclassifications where companies are unwilling. This study provides useful insights in both regards. It found that pharmaceutical companies and distributors vary in their interest in reclassification, influenced by company factors, product factors and external factors. While many company factors relate directly or indirectly to financial return, some do not, and this study identified a degree of complexity in how these factors interact at local, regional and global levels.

The importance of likely revenue yield for companies is unsurprising, given the commercial environment in which pharmaceutical companies need to maximize their earnings and margins in the prescription market versus the non-prescription market. ${ }^{26,27}$ The findings of the importance of product factors affecting both approvability and saleability reflects considerations during earlier drug development, for example the initial 
drug development phase. ${ }^{46}$ Other examples exist of maximizing earnings over human need, for example in focusing research and development efforts on common conditions in high-income countries rather than on diseases predominantly affecting developing countries. ${ }^{47}$

Similar to some of our findings, Haverkost ${ }^{27}$ in 1985 commented on company sensitivity to doctors' views, the importance of postreclassification saleability, the company's product pipeline, and company capability with non-prescription medicines affecting reclassification. Haverkost called reclassification a "marketing man's dream", suggesting that it could fund research and development for new medicines. In contrast, 30 years on, we found multiple instances of commercial failure, possibly because straightforward reclassifications with large market potential have become rare.

For medicines such as (non-emergency) oral contraceptives, with established safety and usage data, barriers to reclassification may unnecessarily burden consumers, society and health funders, hinder achievement of public health goals (e.g. reduced unplanned pregnancy) and limit community pharmacy's primary care role. Therefore, consideration is needed on how some of the barriers found in this paper can be addressed. Pharmacy organizations could consider advocating for such changes to aid their population's access to medicines. Third parties such as pharmacy organizations or consumer groups could work with industry to encourage reclassification or share risk or resources. An example of that is underway with Ibis Reproductive Healthcare partnering with HRA Pharma to try to reclassify the non-emergency oral contraceptive in the $\mathrm{US}^{48}$

To encourage non-prescription access to medicines, governments could modify barriers to reclassification such as cost, time and loss of prescription reimbursement on reclassification. Incentivizing reclassifications, such as by providing sufficient market exclusivity to applicants, 
e.g. for 3-5 years, could help, particularly for products long off-patent, or with a niche market. The finding that market exclusivity might delay a pharmaceutical company driving reclassification for a product early in its patent life, particularly where reimbursement post-reclassification was affected, should be borne in mind, e.g. with a delayed market exclusivity period following the patent expiry.

Different models of reclassification or supply may encourage reclassification. Our findings suggest that the resource required, potential legal challenge, reclassification process, and consumer labelling requirements (e.g. where a pharmacist will not necessarily be involved in supply) are deterrents in some countries. Following the Danish government reclassification of the emergency contraceptive in 1989, the sponsor withdrew its product, ${ }^{37}$ and this study found that product withdrawal could still be an option if they did not want a reclassification. However, we have found countries in which government-driven reclassification has been used to aid consumer access to medicines, as in Singapore and NZ. Thirdparty reclassification has provided most reclassifications in recent years in NZ. In 2015, it was used by a pharmacist who successfully applied to reclassify naloxone in Australia. ${ }^{49}$ Pharmacy organizations could consider whether this model could work in countries where low reclassification activity hinders consumer access.

Models other than national reclassification have enabled supply of some medicines without prescription, e.g. non-emergency oral contraceptives in California, ${ }^{50}$ and patient group directions have enabled pharmacists to increase their role in primary health care in the UK. ${ }^{51}$ Pharmacist prescribing has also been spreading internationally. ${ }^{52}$ Reclassification might become less relevant in the future in some markets with the rise of alternative models to aid consumer access to medicines and better utilize the pharmacist, and the multiple barriers to companies driving 
reclassifications. Pharmacy organizations might want to follow countries such as the US and UK in developing alternative models of supply, although these can sometimes result in more sporadic availability than a reclassification. ${ }^{2}$

Financial effects emerged strongly in this paper. Pharmaceutical companies are not alone in this motivation, with financial interests of the consumer, doctor, pharmacy and government influencing reclassification, as discussed elsewhere from this research. ${ }^{38,41}$

Other commentators and researchers have tended to focus on just 1 or 2 factors affecting reclassification, ${ }^{31,34,53,54}$ which risks missing important and interacting influences on reclassification. We are the first researchers to our knowledge to comprehensively study perceived effects on reclassification, identify how regional and global factors influence movement towards widening consumer access to medicines, and consider third-party reclassification and government reclassification.

Our previous papers ${ }^{38,41}$ have outlined strengths and limitations of this research. We used a single interviewer knowledgeable in the field. Her starting belief was that reclassification with a favorable risk-benefit profile is desirable. We have attempted to be faithful to participants' voices by using their interviews and quotations systematically to document all potential enablers and barriers, with balance in analysis and reporting. We triangulated the lead author's interview analysis with other data sources and checked our analysis with participants. The quantity of data generated only allows this paper to report general findings. We traded some depth for the breadth afforded by incorporating data from nine countries. In Japan, use of interpreters compromised the volume of data that could be obtained, so reclassification driven by non-sponsors could not be explored there. The semi-structured interview approach meant that not all respondents were asked identical questions; however, this approach allowed flexibility to explore particular issues in more detail. 


\section{Conclusions}

Whether or not industry drives reclassifications affects consumer access to medicines and the pharmacist's role in primary care. The pharmaceutical industry drives most applications to reclassify medicines from prescription to non-prescription availability, amid a complex array of financial, capability, organizational structure and focus, and other considerations, and variation in product factors. For countries seeking to encourage self-care, company- and product-related barriers exist to non-prescription availability. Many reclassifications are costly for the applicant, with uncertain and delayed financial return for companies. Public policy initiatives such as market exclusivity, different mechanisms for supply, and encouraging government or third-party reclassification applications could minimize some of these barriers.

\section{References}

1. Blenkinsopp A, Bond C. Over the counter medication. London: British Medical Association Board of Science; 2005.

2. Gauld N. Why the resurgence of OTC reclassifications in the UK is a good thing. Clinical Pharmacist. 2017;9.

3. Paudyal V, Hansford D, Cunningham S, Stewart D. Over-the-counter prescribing and pharmacists' adoption of new medicines: Diffusion of innovations. Res Social Adm Pharm. 2013;9:251-262.

4. Rutter P. End pharmacists' monopoly on selling certain drugs. BMJ. 2015;351:h3415. 
5. Gauld NJ, Kelly FS, Kurosawa N, Bryant LJM, Emmerton LM, Buetow SA. Widening consumer access to medicines through switching medicines to non-prescription: A six country comparison. PLOS ONE. 2014;9:e107726.

6. Braund R, Henderson E, McNab E, Sarten R, Wallace E, Gauld N. Pharmacist-only trimethoprim: pharmacist satisfaction on their training and the impact on their practice. Int J Clin Pharm. 2016;38:1357-1361.

7. Braund R, Ratnayake R, Tong K, Song J, Chai S, Gauld N. Pharmacists' views and experiences on sildenafil supply without prescription [submitted]. 2017.

8. Paudyal V, Hansford D, Cunningham S, Stewart D. Pharmacists' adoption into practice of newly reclassified medicines from diverse therapeutic areas in Scotland: A quantitative study of factors associated with decision-making. Res Social Adm Pharm. 2014;10:88-105.

9. Kux L. Using innovative technologies and other conditions of safe use to expand which drug products can be considered nonprescription; public hearing. Federal Register. 2012;77:12059-12062.

10. Editorial. The case for preventing ovarian cancer. Lancet. 2008;371:275.

11. Editorial. OCs o-t-c? Lancet. 1993;342:565-566.

12. Trussell J, Stewart F, Potts M, Guest F, Ellertson C. Should oral contraceptives be available without prescription? Am J Public Health. 1993;83:1094-1099.

13. Grossman D, Fuentes L. Over-the-counter access to oral contraceptives as a reproductive healthcare strategy. Curr Opin Obstet Gynecol. 2013;25:500-505.

14. Grindlay K, Foster DG, Grossman D. Attitudes toward over-the-counter access to oral contraceptives among a sample of abortion clients in the United States. Perspect Sex Reprod Health. 2014;46:83-89.

15. Grossman D, Grindlay K, Li R, Potter JE, Trussell J, Blanchard K. Interest in over-the-counter access to oral contraceptives among women in the United States. Contracept. 2013;88:544-552.

16. Committee opinion no 544: Over-the-counter access to oral contraceptives. Obstet Gynecol. 2012;120:1527-1531. 
17. Over-the-Counter Oral Contraceptives. American Academy of Family Physicians; 2014 Available at: http://www.aafp.org/about/policies/all/otc-oral-contraceptives.html. Accessed 14 Aug 2017.

18. RCOG statement on the widening of access to the pill. Royal College of Obstetricians \& Gynaecologists; 2007 Available at: https://www.rcog.org.uk/en/news/rcog-statement-on-the-widening-of-access-to-the-pill/. Accessed 27 Feb 2016.

19. Gardner JS, Miller L, Downing DF, Le S, Blough DK, Shotorbani S. Pharmacist prescribing of hormonal contraceptives: results of the direct access study. J Am Pharm Assoc. 2008;48:212-226.

20. Parsons J, Adams C, Aziz N, Holmes J, Jawad R, Whittlesea C. Evaluation of a community pharmacy delivered oral contraception service. J Fam Plann Reprod Health Care. 2013;39:97-101.

21. Grindlay K, Burns B, Grossman D. Prescription requirements and over-the-counter access to oral contraceptives: A global review. Contracept. 2013;88:91-96.

22. Potential candidates for reclassification from POM to P: Royal Pharmaceutical Society of Great Britain; 2002.

23. WHO guidelines for the regulatory assessment of medicinal products for use in self-medication. World Health Organization; 2000 Available at: http://apps.who.int/medicinedocs/pdf/s2218e/s2218e.pdf. Accessed 12 Apr 2013.

24. Lyon G. New game, old competencies: The outlook for OTC. Int J Med Mark. 2001;1:236.

25. Bessell TL, Hiller JE, Sansom LN. 'Pharmacist only' medicines. Aust NZ J Public Health. 1999;23:661-662.

26. Stibel G, Kapoor G. The future of Rx-to-OTC switches. Pharm. Exec. 2002;22:98.

27. Haverkost LF. How industry assesses and picks suitable candidates for switch. Drug Inf J. 1985;19:133-138.

28. Schondelmeyer SW. Economic aspects of switch. Drug Inf J. 1990;24:57-66.

29. Mahecha LA. Rx-to-OTC switches: trends and factors underlying success. Nat Rev Drug Discov. 2006;5:380-385.

30. Achanta AS, Willey Temkin C, Rhodes CT. Attitudes and Opinions Towards Regulatory Aspects of Non-prescription Medicines. Clin Res Regul Aff. 2003;20:1-14. 
31. Armstrong ME. Plan B contraceptive and the role of politics in medicine: a comparative analysis of the "switch" of emergency contraception from prescription to non-prescription in the United States, France, the United Kingdom, and Canada. bepress Legal Series2006.

32. Nguyen NT, Cook DM, Bero LA. The decision-making process of US Food and Drug Administration advisory committees on switches from prescription to over-the-counter status: a comparative case study. Clin Ther. 2006;28:1231-1243.

33. Cohen J. Switching omeprazole in Sweden and the United States. Am J Ther. 2003;10:370-376.

34. Gilbert A, Rao D, Quintrell N. A review of pharmaceutical scheduling processes in six countries and the effect on consumer access to medicines. Int J Pharm Pract. 2006;14:95-104.

35. United States Government Accountability Office. Nonprescription drugs. Considerations regarding a behind-the-counter drug class.2009.

36. United States General Accounting Office. Nonprescription Drugs: Value of a Pharmacist-Controlled Class has Yet to be Demonstrated. Washington, D.C.1995.

37. Juul P. Prescription-to-OTC: is Denmark a model for the world? Swiss Pharma. 1991;13:100-104.

38. Gauld NJ, Kelly FS, Emmerton LM, Buetow SA. Widening consumer access to medicines: A comparison of prescription to nonprescription medicine switch in Australia and New Zealand. PLoS ONE. 2015;10:e0119011.

39. Gauld N, Emmerton L, Kelly F, Buetow S. A new model of prescription to nonprescription reclassification: the calcipotriol case study. Clin Ther. 2012;34:1324-1332.

40. Spencer HM. The Rx-to-OTC switch of Claritin, Allegra, and Zyrtec: an unprecedented FDA response to petitioners and the protection of public health. Am Univ Law Rev. 2002;51:999-1050.

41. Gauld NJ, Bryant LJM, Emmerton LM, Kelly FS, Kurosawa N, Buetow SA. Why does increasing public access to medicines differ between developed countries? A qualitative comparison of factors. J Health Serv Res Policy. 2015;20:231-239.

42. Thorne SE. Interpretive description: qualitative research for applied practice. 2nd ed. New York: Routledge; 2016. 
43. Patton MQ. Qualitative Research and Evaluation Methods. 3rd ed. London: Sage Publications; 2002.

44. Malik K. Human Development Report 2014. New York: United Nations Development Programme; 2014.

45. Morse JM. What's wrong with random selection. Qual Health Res. 1998;8:733-735.

46. Lockhart M, Babar Z-U-D, Carswell C, Garg S. New Zealand's Drug Development Industry. Int J Environ Res Public Health. 2013;10:4339.

47. Henry D, Lexchin J. The pharmaceutical industry as a medicines provider. Lancet. 2002;360:1590-1595.

48. Ibis announces groundbreaking partnership with HRA Pharma to move a birth control pill over the counter. Ibis Reproductive Health; 2016 Available at: https://www.ibisreproductivehealth.org/news/ibis-announces-groundbreaking-partnership-hra-pharma-move-birthcontrol-pill-over-counter. Accessed 25 Aug 2017.

49. Brunswick pharmacist rattles TGA cage to save lives. The Pharmacy Guild of Australia; 2015 Available at: https://www.guild.org.au/news-events/recent-activity/blog-post/recent-activity/2015/10/20/brunswick-pharmacist-takes-initiative-tosave-lives. Accessed 13 Oct 2016.

50. Dembosky A. California women can soon skip the doctor to get their birth control. KQED; 2015 Available at: http://ww2.kqed.org/stateofhealth/2015/06/04/california-women-can-soon-skip-the-doctor-to-get-their-birth-control/. Accessed 8 Jun 2015.

51. Paudyal V, Hansford D, Cunningham S, Stewart D. Pharmacy assisted patient self care of minor ailments: A chronological review of UK health policy documents and key events 1997-2010. Health Policy. 2011;101:253-259.

52. Emmerton L, Marriott J, Bessell T, Nissen L, Dean L. Pharmacists and prescribing rights: review of international developments. $J$ Pharm Pharm Sci. 2005;8:217-225.

53. Francesco S. Has the UK replaced the US in OTC leadership? Pharm. Exec. 1995;15:76.

54. Lyon G. The Rx to OTC switch - creating the climate for change. In: Blackett T, Robins R, eds. Brand Medicine. New York, USA: Palgrave; 2001:47-59. 


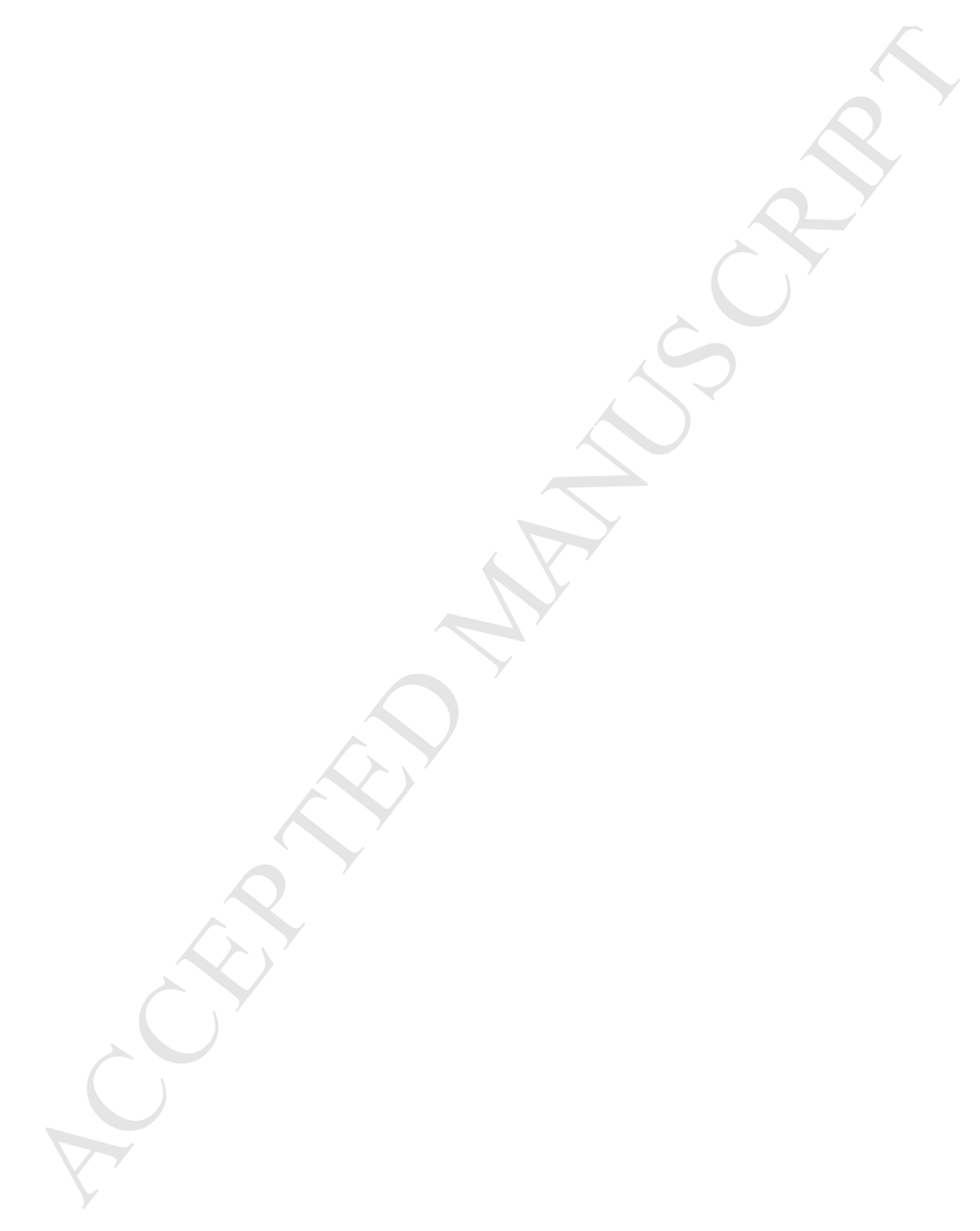


Figure 1. The trilogy of overarching factors causing variability in reclassification in developed countries

[this figure has been provided separately in colour for the online version and black and white for the print version]

Figure 2. An example of how pharmaceutical industry factors can interact with product factors and local factors from New Zealand

[note there is a colour and a black and white version]

[for the colour version the figure should include the following immediately below the figure:] Green represents enabling factors, red represents hindering factors, and orange represents factors that can vary. OTC $=$ over-the-counter. This diagram is not intended to be exhaustive of all factors in the New Zealand environment.

[for the black and white version the figure should include the following immediately below the figure:]

The dotted line represents enabling factors, the solid line represents hindering factors, and the dot and dash line represents factors that can vary. OTC=over-the-counter. This diagram is not intended to be exhaustive of all factors in the New Zealand environment. 


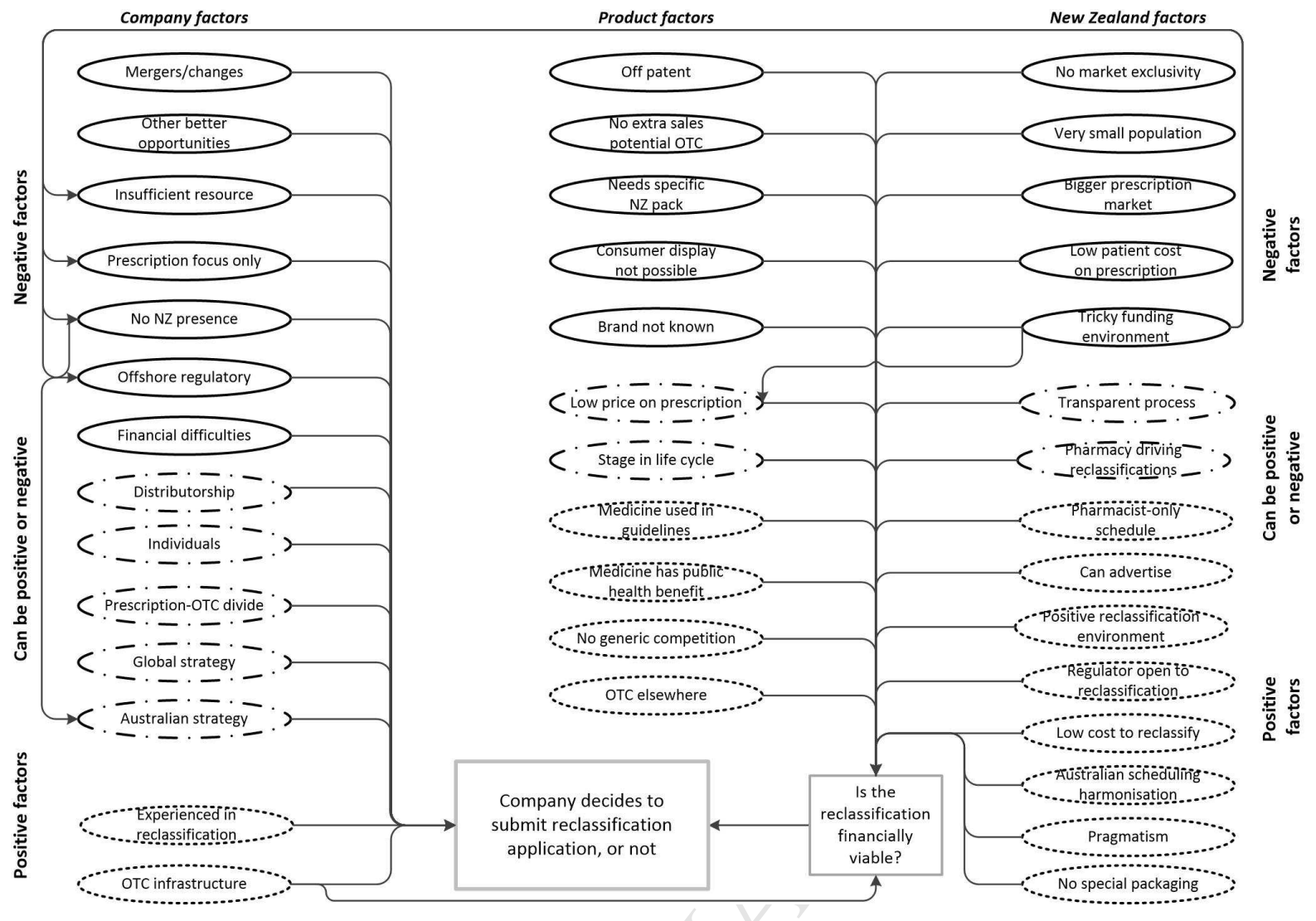




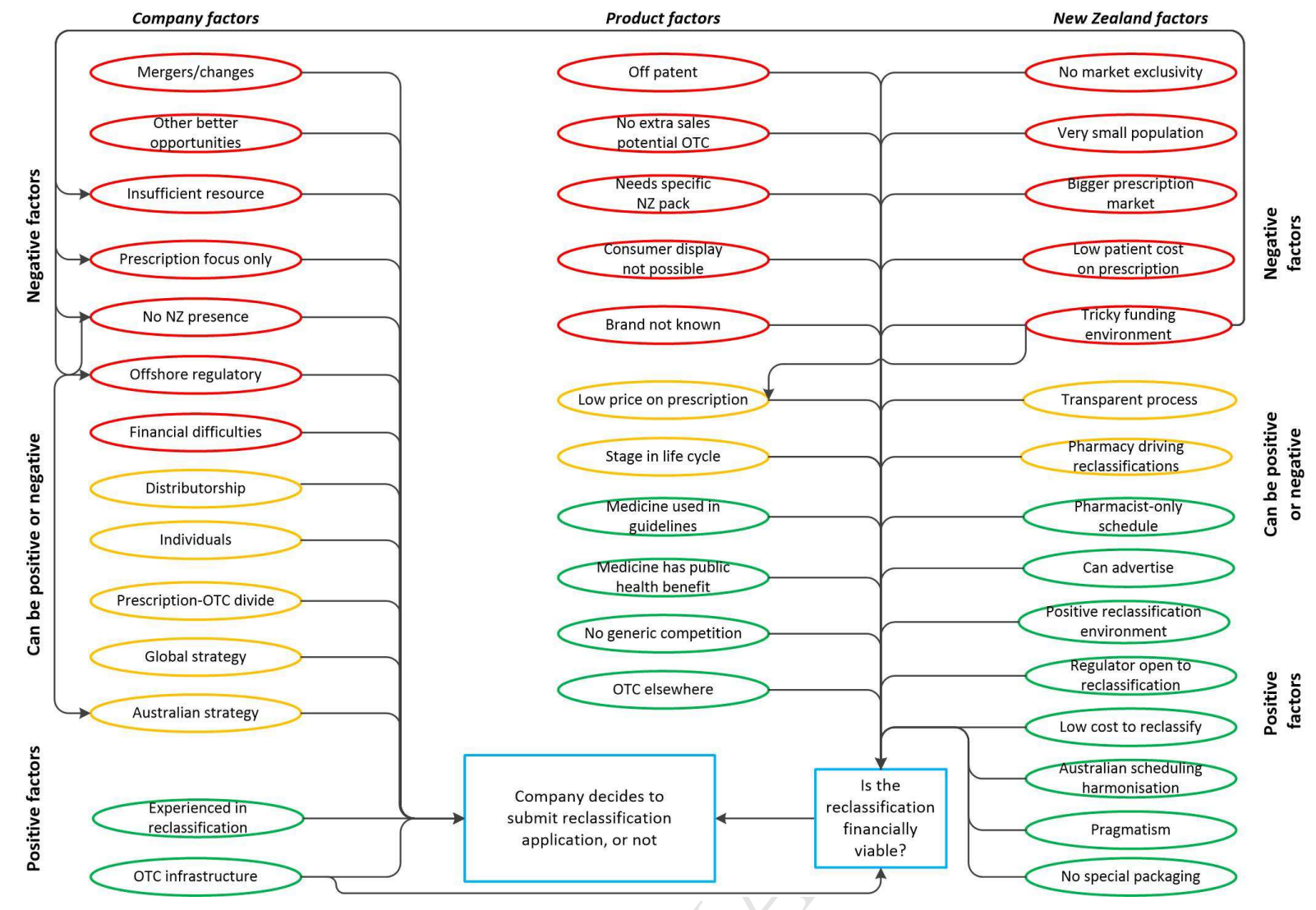




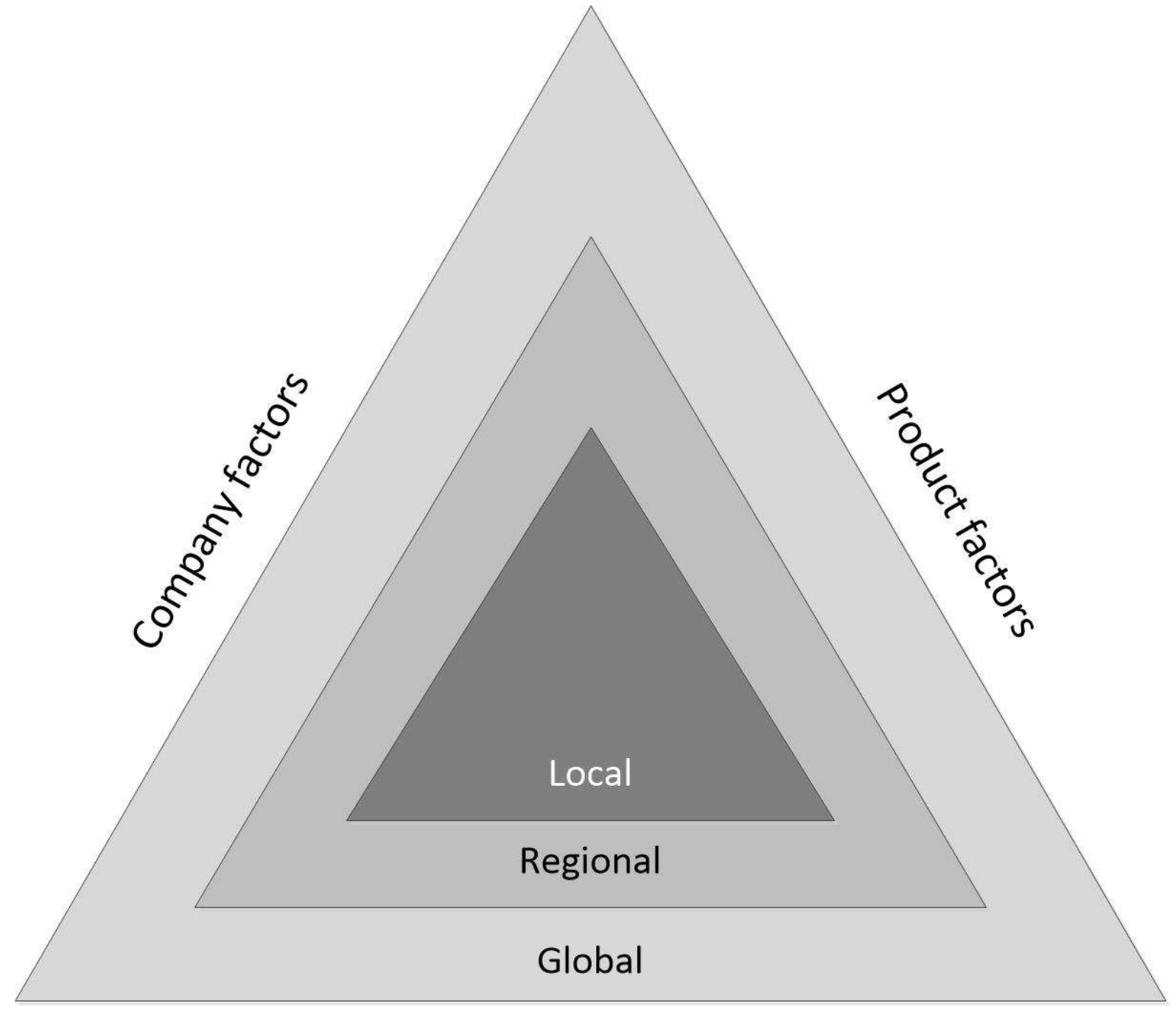

External factors 


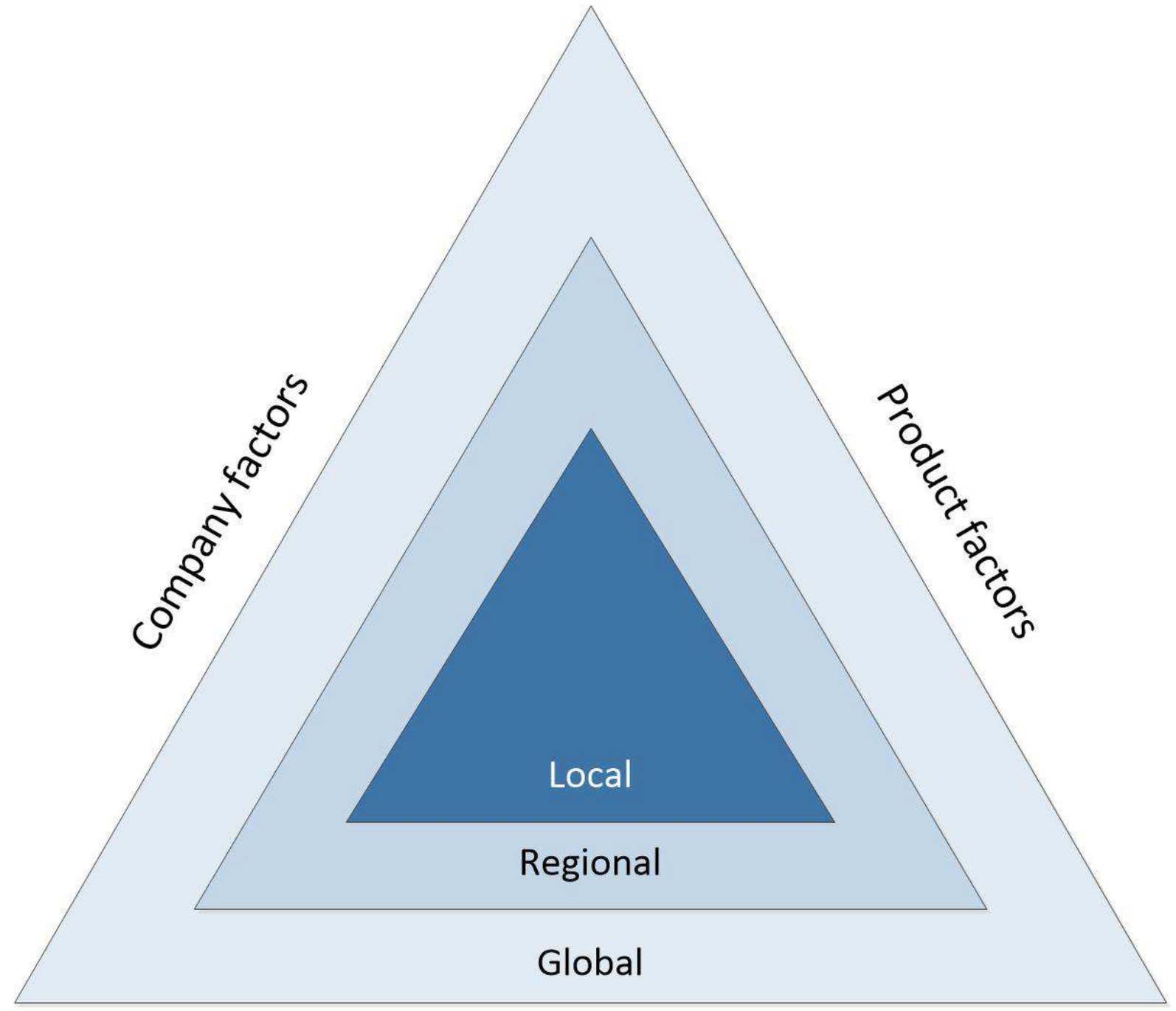

External factors 
Panel 1. Basic lines of inquiry (interview guide)

- His/her role/the organisation's role in medicine reclassification

- Where he/she considered their country sat in reclassification from prescription to nonprescription compared to other developed countries, and why this was

- Contributing factors to the differences between their country and other countries in classification decisions

- Barriers and enablers to reclassification in their country

- Which country he/she thought was advanced in reclassification and what they thought made it different from their country (if known)

- Views on why NZ and Australia sometimes make different decisions (for relevant participants)

- Views on non-sponsors driving reclassification, e.g. government or pharmacy organisations

- Views on the classifications used for medicines in their country

- Views on market exclusivity for medicines that are reclassified 